\section{The Value of Visual Disaster Records from Digital Archives and Films in Post- 3/11 Japan}

\author{
Hiroki Takakura ${ }^{\text {ac}}$, Sébastien Penmellen \\ Boret $^{\mathbf{b c}^{*}}$
}

${ }^{a}$ Tohoku University, Center for Northeast Asia

Studies, Kawauchi 41, Aobaku, Sendai, Japan

bTohoku University, International Research Institute of Disaster Science, Aramaki 468-1, Aobaku, Sendai, Japan

'Tohoku University, Graduate School of Environmental Studies, Aramaki 468-1, Aobaku, Sendai, Japan

Received: September 19, 2020 / Accepted: December 31, 2020

\begin{abstract}
This paper explores the value of visual records from natural disasters in assisting reconstruction, including photography, single-shot videos, and documentary movies. It considers three types of visual records related to the Great East Japan Earthquake: 1) raw data, 2) edited educational videos, and 3) commercial documentary films. It also considers the nature of disaster records and their repository medium, including digital data archives, public educational websites, and commercial networks. Furthermore, the authors consider the overlaps between these categories. Raw video records certainly meet the needs of either digital archives or documentary movies. However, commercial documentary movies form a category of their own, as copyright and scripts constrain their exploitation and manipulation. In conclusion, this paper identifies the merit of each type of visual record and argues that both are necessary for the social remembering of disasters and to help reconstruct communities affected by such events.
\end{abstract}

Keywords: digital archives; films; disaster

\footnotetext{
Corresponding Author

Tel.: $+81 \quad 022-752 \quad-2153 ; \quad$ Fax.: $\quad+81$ 022-752-2153; E-mail: boret.irides@gmail.com
}

\section{Introduction}

Scholars have called the year 2011 the dawn of a new era for digital disaster archiving [1]. In Japan, the digitization of disaster records began in earnest after the national government recognized the importance and potential of an electronic platform to store vast amounts of texts and digital visual records from the Great East Japan Earthquake [2]. Many digital archives of natural and other types of disasters have since been established in the country [3].

The role of digital archives has gone beyond storing data $[4,5]$. Their activities and visual records impact our understanding of disasters and the whole process of recovery and collective memorialization. They assist in the monitoring of rehabilitation and provide data for safe reconstruction planning of devastated coastlines. They actively help to share the information necessary to draw lessons from the behavior of the tsunami and the people affected by it. Archival material has contributed to the development of narratives in memorial centers and disaster museums, as well as an overall stimulus for local, regional, and national tourism [6]. In this sense, they contribute to the economic revitalization of disaster areas and guide reconstruction narratives and efforts.

Why is it particularly imperative to keep visual records of disasters? First, imagery provides the viewer with vivid information about a past catastrophe and the damages suffered by its victims, which is otherwise difficult to imagine. Imagery also complements other types of disaster records such as writing, storytelling, monuments, and the landscape $[7,8,9,10]$. These media reflect the creator's intentions. That is, both written text and pictures are abstractions that discard unnecessary elements. Before there were cameras, this was how human societies kept records. In the present paper, we seek to examine these records to contemplate past disasters and the lessons they offer.

The media created by cameras and video recorders are very different from words and pictures. The subject and its entire sphere of influence are optically projected and fixed instantly on the film, creating meaning in and of itself. These media are characterized by a low degree of abstraction [11]. Compared to records that are written or drawn, video represents a systematic collection of information that goes beyond (or disregards) the person behind the camera. Of course, this difference affects what media researchers use and what meanings they associate with them.

In contemporary society, visual amateur imagery has entered the collective disaster record. Digital cameras and videos are widespread. Anyone with a smartphone can record images. Even news channels covering typhoons, floods, and other significant disasters, use footage provided by viewers. Reflecting this trend, the Great East Japan Earthquake has been the subject of a vast number of visual recordings. The items include videos taken by citizens on their mobile phones, mass media, researchers, filmmakers, and other 
products for television and film. While video and film are difficult to differentiate precisely, a video refers to the medium where a series of photos taken with a video camera (including mobile phones) appear to be moving. Much of it is accessible through the expansive digital archives available on the Internet. Filmmaker Fujii Hikaru estimates that 800 documentary movies were produced within the two years that followed the disaster [12].

The purpose of this paper is to explore the meaning of visual disaster records and offer a comparative analysis of different media: photographs, videos, and film. Since the Great East Japan Earthquake, disaster scholars have reiterated the importance of collecting, preserving, and sharing digital disaster archives $[2,3,13,14,15,15,16]$. However, there are few comprehensive and critical examinations of such endeavors. The potential and significance of photos and videos for disaster risk reduction are often assumed to be self-evident. Despite the large budgets that have been invested, academics, policymakers, and companies related with disaster digital archives neither fully discuss nor challenge the nature and the purposefulness of disaster archives. For instance, Japanese academic debates rarely critically analyze disaster documentaries. While we may have a massive amount of data, what do we make, for example, of missing information or 'archival silences' from police, fire departments, and the self-defense forces? [17] How do we define disaster data, since the disaster experience is both personal and subjective in terms of when the "present" ends? [18] When considering the significance of disaster records, we must first reconsider how digital archiving benefits society $[19,20]$. We should analyze the specific roles played by photos, videos, and films and their relationship to other disaster records.

This approach is also the foundation of the book "Door of disaster documentary film: on sharing memories and records of the 2011 Tohoku Earthquake." Koretsune and Takakura discuss the creative process of disaster documentary film-makers and their impact on society [21]. They explain that the book stems from their involvement in an ongoing film screening project that raised questions about the place of documentary films in disaster research [22]. They organized ten film screenings during the academic year 2018-2019, after each of which Koretsune chaired a discussion with the directors or producers, as well as a researcher familiar with the film's subject. The discussion topics included their motivations for executing the project, the joy and predicament derived from the relationship with people in film, their business strategies, and the role of films in disaster recovery. They took pride in the fact that disaster documentary films proved an influential and unique media that improves our understanding of the social impacts of hazard and creates empathy for resilience in the face of disaster.

Building on this reflection, this study adds an element of cultural relativism to explore the significance and differences between video records. The threshold for making films is today so low that "everyone becomes a filmmaker the moment they hold an iPhone" [23]. People may create simple slideshows, combining photos and a soundtrack that does not differ significantly from the videos. These blurred boundaries between still photographs and animated videos became increasingly apparent as film screenings progressed. Therefore, we believe it is necessary to precisely understand the unique characteristics of the film medium. We also argue that one must understand the differences between films made under a producer's direct supervision and all other videos and photographs. This paper reflects on the way we think about digital disaster archives containing digital pictures and videos. Furthermore, it discusses the characteristics of disaster documentary films, reflecting on both the positive and negative aspects of the potential and significance of digitizing visual disaster records.

This paper reviews the contents of digital archives, disaster documentary films, and literature related to the Great East Japan Earthquake. First, it examines digital archives. Second, it provides a critical overview of video archives. Third, it investigates the attributes of disaster films. The paper concludes with a critical discussion of visual recordings based on the notion that in all their forms, the viewer will only learn a partial truth.

\section{Digital Archives}

One of the leading archives of the 2011 earthquake and tsunami is the Michinoku Shinrokuden Great East Japan Earthquake archive, curated by the International Institute of Disaster Science, at Tohoku University. It is an electronic repository in which visual images, photos, sound recordings, texts, and reports are stored and made available to the public. According to its design, the archive will collect data for a limited period of ten years ending in March 2021. Michinoku Shinrokuden results in a broad industry-academia collaboration involving over 120 institutions, including the National Diet Library, NHK, IBM, and Harvard University. It also benefits from civic participation, such as contributions from disaster victims and the public. The sheer amount of data shared across this network cannot be easily grasped. For civic participation, for example, 20,00o photos and 800 interviews were collected from locals in February and March 2012. As of 2013, there were between 200,000 to 300,000 published and unpublished photos. Since 2013, approximately 100,ooo have been made public $[13,16](1)$.

The photographs' data (e.g., GPS, time, and date) can be used to list all photos taken of a particular building at different times and by various people. Voice recognition technology has been used to transcribe the content of news programs. Digital photos are tagged with information such as image size, resolution, date and time, focal length, F-value, exposure time, latitude/longitude, and the shot direction. In combination with text information, users can search in multiple directions to find the desired data [14]. Visual image data, which mostly consists of photos, provide temporal and spatial information that lends insight into what happened during a disaster and its aftermath. The metadata gleaned 
from photos of the same building gives us a moment-bymoment account over time.

Conventionally, archives are repositories of official documents and historical materials, written records produced by government offices and historically significant materials, and institutions that organize, store, and make information public. While we have come to refer systematically to "digital archives" in Japan, English speaking countries may also refer to those as "digital cultural heritage" [24]. Digital cultural heritage is a computerized collection of materials with a permanent value that needs maintaining for future generations (2). Although there is the problem of replicability with digital data, users should not be able to modify archival materials from their original and unique forms. It is also essential to create sustainable digital archives to ensure the continued accessibility of their material [18]. While a photo may be too fragmentary to provide a complete understanding of a situation, users can bundle related data together to create meaning that goes beyond a single piece of data. The essence of a digital archive lies in the ability to search limitlessly and cluster related data together. It demands that the users "understand how and what and when photographs (and footage) communicate information across space and time" [25].

A digital archive has value in and of itself as a system that can accommodate users who want to explore something. Harada, a visual sociologist, explains the social origin and value of digital archives as follows: As humans, we are in the habit of collecting things out of intellectual curiosity, and we do so more or less systematically. The resulting personal databases allow us to understand the world in our ways in the course of daily life and to connect with others. In accumulating these databases by, for example, (digitally) archiving visual images that members of the community have taken and contributed, "people become self-aware of how their actions (over time) form a unique body of poetry, aesthetics, and ethics" [26].

\section{Video Archives}

Considering that television images are serial arrangements of say, 30 photos per second, we might say that pictures and videos are both based on optical principles. However, the records differ in both nature and societal impact. This difference transpires in the digital archive's use. Photos can be searched freely from among other types of media and may be listed as part of a clustered group of materials. They can easily integrate other groups or categories of data. On the other hand, although a video is collected in digital archives in the same way, the effective use or public presentation of a video depends on databases specializing in visual images or on visual image archives. That is, rather than being a matter of the data itself, it is a matter of the human ability to understand the data. Video records inevitably include the element of temporal continuity, and a person cannot understand the content without watching the entire video.
Perhaps the most representative educational video archive is the NHK's Great East Japan Earthquake Archive (3). It is an archive of news coverage of the disaster and recovery, eyewitness accounts, and programs for future disaster prevention. Visual images are divided into three categories: disaster, recovery, and lessons learned. The disaster category is further subdivided into visual images from 3/11: $72 \mathrm{~h}$ from the earthquake, 1,073 testimonials about that day, 31 testimonial summaries, 161 voices from the disaster area, and 136 clips from the day of the disaster. Visual image files may be viewed under each subcategory. Users can search for videos by keyword to obtain data for a particular purpose. However, these videos can be best understood when viewed in the light of the system developed by the NHK. It gives meaning and order (hierarchy) to the data to provide information and disaster education to its audience. It is somewhat different from the experience of being able to freely mine and cluster all kinds of data from photos and other disaster digital archives for the user's purpose.

Digital archives curators may provide accessibility and information that allows their usage and interpretation by regular users. Unlike photographs, the temporal continuity of videos limits the fragmentation of their meaning. However, a video's medium demands that the viewer understands its inherent meaning. This idea is perhaps best demonstrated by the fourteen news clips from the NHK Broadcasting Center in Shibuya-ku, Tokyo, after 2:48 pm on March 11, 2011. The viewer sees images of tsunamis rolling over rice paddies and experiences the trembling voices of nervous announcers or the loud noise of helicopters. In theory, any user could browse such videos to determine their relevance and bundle them to fit their purposes. In practice, the systematic organization by curators facilitates data viewing regardless of the intention of the user. This method assumes the existence of some common understanding wherein the user can agree with the categories provided. In contrast, such an agreement may not be necessary when a user searches digital archives with a given purpose. In this case, the repository archives provide users with indexed results or a particular configured chunk of information feeding his or her unique needs.

The NHK's archive contains 1,073 recorded video testimonies. A clip broadcast on June 5, 2017, titled "My husband's life was taken by the tsunami" shows a closeup of a female interviewee. She recalls being saved from the waves and explains how she put her husband's body to rest in a grave. The webpage shows a map and information, including the speaker's name and the title of the broadcast. Also, the audio content from each testimonial has been transcribed in collaboration with Michinoku Shinrokuden. Tagged information such as time, date, and place and written transcriptions are helpful references when we try to understand the testimonials' larger meaning. Video archives work well in cognitive communities that share a singular history, whereas digital archives of photos and other media are open to a broader range of users.

On the other hand, the value of these videos as disaster records are the voices, facial expressions, and silence of the 
participants as they try to condense the experience of a moment or several years. They provide the viewer with intangible information together with text and some degree of assigned meaning. A video notably contains unsearchable (at least for now) information that cannot be tagged or turned into a text without losing some of its subjectivity and communication power.

Another similar collection of testimonials is the Tsukuba Visual Images Archive. This archive is the product of a collaboration of disaster victim assistance groups, anthropologists, and photographers. It contains visual images of interviews with assistance groups, and people relocated to Tsukuba City after the Fukushima nuclear disaster. The videos were collected on the video-sharing site Vimeo [27, 28]. Among these videos, we would like to highlight one that shares the experience of a man narrating his survival of the tsunami. As he was about to be swallowed by the waves, he recalls falling into a ditch about two meters deep. He looked from there to only see a 10-meter-high wave dragging debris above him (4). His testimony lasts for only $20 \mathrm{~s}$. However, it is a rare eyewitness account of the tsunami, as seen from the ground of the flooded area. This matter-offact statement at a time when he was presumably facing death leaves a lasting impression and memory with viewers.

Disaster testimonies convey the lived experiences and thus contribute to disaster prevention. A short video of the surviving witness of a tsunami can deliver powerful messages and meanings (5). It may be only a small fragment of the overall disaster, but its value is inherent to the human experience. It differs from photographs and texts where the significance tends to depend on the individual's knowledge, imagination and purpose. The overwhelming number of videos makes it impossible for us to carry out any type of survey or draw a generalized overview. Instead, we must rely on the archival organization set out by the video's creators, or work with chance encounters and groupings based on limited searchable data categories such as location or activity.

\section{Film Attributes}

In practice, the distinction between video and film seems complicated. A good example is the archive project run by the Center for Remembering 3/11 ("Wasuren!") under the auspices of the Sendai Mediathèque. The project began on May 3, 2011, following the Great East Japan Earthquake. The curators and librarians of the center manage the digital archiving project in collaboration with residents, specialists, artists, and staff members. Together, they launch, record, and archive the recovery efforts independently using a significant number of visual images contained in the database.

The disaster archive "Remembering 3/11" has a studio and a broadcasting station on-site and lends out equipment for recording, editing, and releasing videos (6). Edited photos and videos can be viewed from the project's homepage. The project creates DVDs from these videos. Each video is labeled with the title, the name(s) of the producer(s), and the date of production. These DVDs cannot be streamed or downloaded from the Internet. They can be viewed on-site via the library's intranet database or checked out as a hard copy. Only then the viewer learns that the videos have been compiled by project participants.

The homepage of the Center for Remembering 3/11 lists the video's visual materials (including photos) and films on the same page. The center itself does not distinguish between them. On the website, the curators state that both visual materials are equally important and that the distinction between them is almost unnecessary. Their search engine provides only minimum information via thumbnails. People do not know if it is either a film or a video archive until they visit the Center to watch the item.

Challenging this lack of distinction, the authors of the present paper believe that if we consider it theoretically, we might gain a new perspective on the meaning of visual disaster records by considering the dichotomy from a more abstract or theoretical approach.

The first difference between videos and films is their commercial value or lack thereof. The DVDs produced by "Remembering $3 / 11$ " are not freely available for viewing on the Internet or outside the Sendai Mediathèque. They are produced together with the city of Sendai. There exists a close relationship between film and commercial activity, which can prevent access to information (7). The cost of a documentary film is covered by private funds from the filmmaker and audience (8). In contrast, disaster digital archives aim to make educational videos and other materials freely available.

The critical attributes of digital archiving are its unlimited searchability and capacity to cluster items. The format of the documentary film denies this sort of useroriented approach. It is a collection of meanings derived from existing individual videos. The filmmaker regulates the video footage and sequence via editing. Digital archives allow the user to structure information and thus sequence videos in line with their particular purpose. In the case of a video archive, if the curator has created a particular table of contents that serves as a record, users can, to some degree, freely group various videos as they see fit. In the case of photo and written information, structuring is possible even if the users do not share such awareness. They can create collections in line with their objectives and find value therein. The valuation of data is entirely dependent on the user. This process presumes the originality and uniqueness of the data.

Films are different. The intent of the creators (e.g., videographer, editor, director, producer) is absolute in terms of making and structuring the sequence of footage/data. If the visual footage is kept at hand, it can be used as a film material. However, if one gives footage to the public digital archive, it would become data. Unlike data, footage cannot be reordered at will by the viewer/user without changing its nature. Directors place value on visual images. Of course, a film can be interpreted in various ways, and despite the director's intent, there can be no single understanding. Interpretation is open to the user. Still, one cannot 
understand the sequence and collection of footage without considering the director's intent. Therefore, we can describe a documentary film as "a piece of fiction that results from accumulating fragments of facts captured in visual images and reconstructing the original meanings of those facts to derive different meanings" [29].

Does this mean that films hold no value as disaster records? Not at all, see, for example, Nuclear Cattle [30], Akahama Rock \& Roll [31], and other films discussed in Koretsune and Takakura's book [21]. Such films present a kind of truth that the directors want viewers to derive from their works of reconstructed "fiction." Indeed, films are subjective in that they are made with a specific purpose and thus remain subjective. There is also a subjective choice in how to capture an image. Nevertheless, the camera systematically and objectively records the details reflected in its lens, from which viewers can discern information (9). Disasters films are part of the dynamic processes of the social world, which many anthropologists view as a fundamentally fascinating phenomena [32].

The question of fiction relates to an old argument of the negative reliance of film/visual date posed by Margaret Mead's "visual anthropology in a discipline of words" [33]. The anthropological concept of "partial truth" may be relevant here. When ethnographers study certain cultures, they cannot entirely escape their positions/subjectivity during their observations. Data are derived from the relationships between the anthropologist and the people. In other words, objectivity can be achieved only to some degree. It is impossible to describe a culture correctly in an omnidirectional sense [34]. This conundrum does not mean that we ought to abandon our efforts to study/report/understand other cultures as scientists. We must presume that we can only arrive at partial truths, and yet strive for an overall cultural understanding. Furthermore, Takakura explained [35] that, when used appropriately, partial or fragmentary ethnographic truths can foster crosscultural exchange between the respective societies of the researcher and subject.

The notion of partial truth ought to apply to disaster studies and more specifically to disaster archives. No one can ever arrive at a single, absolute picture of a disaster, and we must be conscious of partial truths in our quest [36]. In this sense, digital disaster archives are mechanisms for the omnidirectional gathering of information. Our brains are incapable of understanding the enormous amounts of fragmented information that they contain. Therefore, archives serve as tools to extract "partial truths." In the context of disaster studies, digital archives and films follow similar mechanisms. Digital archives allow users to collect data freely and structure it to ascribe meaning and value for individual purposes. By contrast, films allow the creator to have decisive control over how countless digitized visual image clips are combined.

There is another difference between documentary films and video: their commercial value or lack thereof. Accessing a video archive is simply a personal act. However, the making of a film constitutes an "event" or "process" in a social context. Works are released, variously advertised, and picked up by news media if they earn the accolades of film festivals. Film production is, in this sense, a commercial endeavor, and creators take various measures to disseminate their works in society.

According to Makoto Sato, good documentary films portray the reality of the subject people as well as the attempt by the creator to learn something from those visual images [37]. They present the audience with new perspectives on the world. Koretsune describes how Haruko Konishi, the film director of Akahama Rock $\mathcal{E}$ Roll, the story of survival of a coastal community, became involved in the documentary film because of her search for truth [21]. She derives satisfaction from breaking down her prejudices and stereotypical views during the experience of film making. This process is also described as "awakening" by Satoshi Watanabe, the director of the Silent Revolution [38]. It begs the critical question of whether it is "enough just to save memories and records" [31]. Similar reflections were shared by Umemura, the executive producer of Debris and Radio. The film tells the story of a makeshift radio built by amateurs in the immediate aftermath of a disaster. Their effort provided information to a confused and traumatized community [39]. Hideyuki Yamakuni has repeatedly visited disaster areas even after filming was completed, suggesting the relationships formed were not just for the camera [21]. Film producers collect footage with great effort, meticulous planning, and forging relationships that go beyond the scope of their work. This process is not the same as the collection of fragmentary video snapshots. Of course, documentary films differ in whether they create specific scenarios or are observational $[37,40]$. However, in any case, they are based on long-term relationships with subjects, professional awareness, and a large supporting labor force.

It is also important to note that films presume some sort of presentation at a theater, screening, or film festival. The directors featured in Koretsune and Takakura's 2021 book state that they were conscious of creating a relationship with the audience [21]. The filmmakers organized the free filmscreening events by themselves in various temporary evacuation facilities. They were reported as acts of support for disaster recovery $[41,42]$. Considering how and where a film should be screened is also part of social remembering. In preparation for foreign film festivals, directors add Englishlanguage subtitles and edit visual images to match local social contexts. Tamotsu Matsubara's Nuclear Cattle was initially a 20-minute short narrative before being extended after earning awards at film festivals. Subsequently, the film was edited for overseas screenings. In addition to language, the film was modified to accommodate cultural differences in the interpretation of visual images. This elaboration tells us that, unlike archival video images, the film is relatable. Editability remains in the hands of the creator.

\section{Conclusions}

This paper has focused on the differences between photo, video, and film in contemplating the attributes and meanings 
held by visual disaster records. Of the three media, in the context of visual disaster records (which may vary), photos and videos maintain the originality and uniqueness of the information they contain, and their value as data is heightened when combined with digital archiving. In this regard, we should treat documentary films separately as a kind of social construction. Table 1 illustrates the symmetrical attributes of searchability, originality, accessibility, creativity, evidentiality, purposefulness, and commerciality. Of these, searchability and creativity are perhaps the most significant.

We might also distinguish between scientific or scholarly activities and artistic or journalistic activities. However, when considering the value of visual disaster records, it is not enough to emphasize such differences. Commercial films and educational videos share similar mechanisms of construction, deconstruction and reconstruction. However, this process continues well beyond their creation. At Tohoku University and Harvard's Japan Disasters Archive (jdarchive.org), for instance, documentary films, videos and archives about disasters are used during classes and seminars to discuss, deconstruct and shed light on the multilayered experiences, narratives of destruction and reconstruction of the disaster affected areas (see also [43]). Such an approach may enhance critic and reflexivity within disaster studies and beyond.

Fragments of archived information can only be used if the user has a strong sense of purpose. Digital archives allow us to recognize a unique esthetic, ethical past, and make connections with others. The archive itself becomes a valuable cultural heritage repository, and the UNESCO's Charter on the Preservation of Digital Heritage states that when resources are "born digital" there is no other format but the digital object (10).

Table 1 Attributes of digital archives and films

\begin{tabular}{|c|c|c|c|}
\hline Attributes & $\begin{array}{c}\text { Photo } \\
\text { (digital } \\
\text { archives) }\end{array}$ & $\begin{array}{c}\text { Video footage } \\
\text { (digital } \\
\text { archives) }\end{array}$ & Film \\
\hline Searchability & unlimited & limited & none \\
\hline Originality & $\begin{array}{l}\text { maintaine } \\
\text { d }\end{array}$ & maintained & editable \\
\hline Accessibility & $\begin{array}{l}\text { open } \\
\text { (Internet) }\end{array}$ & $\begin{array}{l}\text { open } \\
\text { (Internet) }\end{array}$ & $\begin{array}{l}\text { closed } \\
\text { (theatres, } \\
\text { film } \\
\text { festivals) }\end{array}$ \\
\hline Creativity & $\begin{array}{l}\text { none, or } \\
\text { weak }\end{array}$ & $\begin{array}{l}\text { none, or } \\
\text { weak }\end{array}$ & strong \\
\hline Evidentiality & strong & strong & weak \\
\hline Purposefulness & $\begin{array}{l}\text { unusable if } \\
\text { not strong }\end{array}$ & $\begin{array}{l}\text { usable even } \\
\text { if none }\end{array}$ & $\begin{array}{l}\text { usable even } \\
\text { if none }\end{array}$ \\
\hline Commerciality & less & less & more \\
\hline
\end{tabular}

In the same way that a disc jockey breaks down music in creating the disco space, a video editor decontextualizes and deconstructs video footage. His mixing of photographs and footage as information becomes essential for its long-term preservation as digital heritage. This speaks to the critical social value of digital archives themselves. Indeed, as with film-making, a digital archive could not be created without strong commitment, purpose, or ongoing collaboration. Likewise, it is not too different from film in its inherent meaning, social exchange creation, and efforts to stimulate the worldviews of the audience.

By discussing their characteristics, we hope to have shown the particular opportunities and limitations of each type of disaster's visual record concerning the construction of broader narratives and stories. In the case of the Center for Remembering 3/11, we have shown how raw videos allow regular citizens the opportunity to contribute visual records about the disaster. In this sense, they become directors and develop their own stories. Their voices add to the diversity of digital records that constitute a lasting collective memory of disasters. As Weisenfeld argues, visual images help us rethink disasters and our society at large in the long term [44].

The significance of keeping various digital visual image records of disaster lies in being able to convey past events to present and future generations, enlighten people who see/use them and create connections across time and space. Digital archives serve as one means to this goal and documentary films as another. They are both essential media that support the basis of disaster prevention and mitigation: remembering the disaster and archiving data for future researchers. We conclude that rather than separating the two, we should think of them as tires on the same vehicle as we contemplate how to collect, structure, and use digital disaster visual images. To that end, we hope to see academia making more significant efforts to integrate film into disaster studies and increase involvement and intervention where it has lacked hitherto.

\section{Acknowledgments}

This paper is one of the research results of the Core Research Cluster of Disaster Science, Designated National University at Tohoku University. We appreciate Sakura Koretsune (Center for Northeast Asian Studies, Tohoku University) and Yu Fukuda (Notre Dame Seisin University) for their efforts in combining modern arts with social sciences.

\section{Notes}

(1) https://www.ibm.com/downloads/cas/WRN5ZOGB (last visited: 2020/5/12)

(2) https://en.unesco.org/themes/information-preservation/digitalheritage/concept-digital-heritage (last visited: 2020/5/15)

(3) https://www9.nhk.or.jp/archives/311shogen/ (last visited: 2020/5/13)

(4) https://vimeo.com/154850039 (last visited: 2020/5/13)

(5) Of course, photos also convey strong messages, as reflected in photos of "decisive moments" [45], but videos have value as disaster records even when they appear to lack a specific message.

(6) https://recorder311.smt.jp/aboutus/ (last visited: 2020/5/13) 
(7) The concept of "film curation" for the archiving of visual images is much like the curation (collection, preservation, exhibition) of works of art [46]. In this sense, just as with the National Film Archive, disaster visual image items can be curated [47].

(8) This is not to say that art has no public nature. It varies by country, and at least in Japan, we must consider the historical origins of public access to science and art.

(9) Although there are various views on evidentiality and digital photos and other visual images, the discussion in this paper presumes the use of visual images with a minimal, conventional analog level of processing [48].

(10) UNESCO Charter Articles 1 and 5 (https://www.mext.go.jp/unesco/oo9/1386520.htm) (Last visited: $2020 / 5 / 20$ )

\section{References}

[1] Gordon A, Morimoto, R. Japan Disasters Digital Archive: Its Evolution and Future Prospects (Nihon saiga dignitary aakaibu no tenkai to tenbou). Journal of the Japan Society for Digital Archive (Dezitaru Akaibu Gakkaishi) 2019; 2-4: 347-352.

[2] Suwa Y. The Current Situation of the NDL Great East Japan Earthquake Archive "HINAGIKU" (Kokuritu tosyokan higasinihon daisinsai aakaibu <Hinagiku> no genzyou). The Journal of Information Science and Technology Association (Joho no kagaku to gijutsu) 2014; 64-9:343-346.

[3] Miura S, Suzuki H, Hotta Y, Usuda Y. Proposal for Collecting, Maintaining and Transmitting Disaster Materials after Disaster Occurrence and for Building a Digital Archive: Based on the efforts of disaster area libraries (Saigai hassei go no saigai siryou no syuusyuu ' seibi - hassin to dezitaru aakaibu koutiku ni mukete no teian - Hisaiti tosyokan, Kokkai tosyokan, kenkuu kikan no torikumi wo humaete). Journal of the Japan Society for Digital Archive (Dezitaru Akaibu Gakkaishi) 2019; 3-2:119-122.

[4] Shibayama A, Boret SP, Sato S, Imamura, F. The Roles of Archiving in Earthquake Studies: The Case of the Great East Japan Earthquake. Proceedings of the 16th World Conference on Earthquake Santiago Chile, January 9-13 2017; p. 1-11, https://www.wcee.nicee.org/wcee/article/16WCEE/WCEE20171639.pdf

[5] Boret SP, Shibayama A. Archiving and Memorializing Disasters: Report of a UN international workshop. Journal of Disaster Research 2016; 11-3:437-442. 10.20965/jdr.2016.p0437

[6] Kitamura M, Murao O, Shibayama A, Activities of Community Archive after the Great East Japan Earthquake: A report on Sendai City Arahama area as an example. Journal of the Japan Society for Digital Archive (Dejitaru Akaibu Gakkaishi) 2018; 22:12-15.

[7] Suppasri A, Abe Y, Yasuda M, Fukutani Y, Imamura F. Tsunami signs, memorials and evacuation drills in Miyagi prefecture after the 2011 Great East Japan tsunami, Esteban, M., Takagi, H. and Shibayama, T. editors. Handbook of Coastal Disaster Mitigation Engineers and Planners, Amsterdam: Elsevier, 2015; p. 599-614.

[8] Boret SP, Shibayama A. The Roles of Monuments for the Dead during the Aftermath of the Great East Japan Earthquake. International Journal of Disaster Risk Reduction 2018; 29:55-62. 10.1016/j.ijdrr.2017.09.021

[9] Fujiwara K, Hata H, Makihara E, Fujihara Y, Nakayama N, Iida $\mathrm{H}$, Matsumoto K. Kataribe: A hosting service of historage repositories. Proceedings of the 11th Working Conference on Mining Software Repositories 2014; 380-383.
[10] Littlejohn A. Museums of themselves: disaster, heritage, and disaster heritage in Tohoku. Japan Forum 2020; April:1-21. Routledge.

[11] Collier J, Collier M. editors. Visual anthropology: photography as a research method, Albuquerque: University of New Mexico Press, 1986.

[12] Fujii H. Mori Art Museum "Catastrophe and the Power of Art" Pre-Discussion Series 2nd "Expressing Disasters with Photos and Images: Records, Artisticity, Morals" Report (Mori bijutsukan 'katasutorofu to bijutsu nochi kara-ten' Pure disukasshon shirīzu dai 2-kai 'shashin ya eizō de sanji o hyōgen suru koto: Kiroku, geijutsu-sei, moraru' kaisai repōto) 2017. https://www.mori.art.museum/jp/news/2017/12/682/ Accessed 12 November 2020

[13] Imamura F. Starting up the Archive of Michinoku-Shinrokuden for the 2011 east Japan Earthquake and Tsunami, and its Future (Higasinihon daisinsai no aakaibu <Mitinoku sinrokuden> no tatiage to kongo). The Journal of information Processing and Management (Joho kanri) 2016; 59-2:123-127.

[14] Imamura F, Sato S, Shibayama A. Michinoku-Shinrokuden: Digital archive project of the 2011 Great East Japan Earthquake Disaster by industry-academia-government-citizen collaboration (Michiinoku Shinrokuden - Sangakukanmin no tikara wo kessyu site Higashinihon daishinsai no Akaibu ni Idomu). Journal of information processing and management (Joho kanri) 2012; 55-4:241-252.

[15] Shibayama A, Kitamura M, Boret SP, Imamura, F. The State and Visions of Disaster Archives as seen from The Great East Japan Earthquake (Higasinihon daisinsai no jirei kara meitekuru sinsai aakaibu no genjyou to kadai). Journal of the Japan Society for Digital Archive (Dezitaru Akaibu Gakkaishi) 2018; 2-3:282-286.

[16] Sugimoto S, Mihara T, Nagamori M. Digital Archives of Great East Japan Earthquake as a Community Archive: Enhancing usability through the linking of archives in open data environments (Komyunitii aakaibu - oopun deeta renkei ni your riyousei no kouzyou). Dezitaru aakaibu Gakkaisi (Journal of the Japan Society for Digital Archive) 2018; 2-4:359-363.

[17] Nagasaka T. Digital Archive of Disasters and its Use in Bone Digital Age (Boon dezitaru no zidai ni okeru saigai no dezitaru aakaibu to sono riyou). Journal of Society of Photography and Imaging of Japan (Nihon syasin gakkaisi) 2016.; 79-1:16-22.

[18] Kawauchi A. Preservation of material related to great earthquake disasters: To the 2011 Great East Japan Earthquake from the 1995 Great Hanshin-Awaji Earthquake ('Rekisi siryou' hozon no torikumi no genjyou to kadai: Hansin-awazi daisinsai kara higasinihon daisinsai he). The Journal of Information Science and Technology Association Association (Joho no kagaku to gijutsu) 2014; 6-49: 377-381.

[19] Harada K. 2019. Niigata Regional Image Archive: Bootstrapping the Community ('Niigata tiiki eizou aakaibu' no zissen wo tousite: Tiiki wo buutu sutorappu suru). Journal of the Japan Society for Digital Archive (Dezitaru Akaibu Gakkaishi) 2019; 34:383-387.

[20] Mizushima H. 2018. Dezitaru aakaibu, tiiki eizou. komyunitii (Digital Archive, local film, Community). Dezitaru aakaibu Gakkaisi (Journal of the Japan Society for Digital Archive) 2(4): 318-323.

[21] Koretsuna S, Takakura H, editors. Door of disaster documentary film: Thinking ways of the sharing of memories through the documentary films of Great East Japan Earthquake (Saigai dokyumentarii eiga no tobira: Higashi nihon daishinsai no kioku to kiroku no kyouyuu wo megutte), Tokyo: Shinsensya; 2021. 
[22] Koretsune S. Thinking ways of the sharing of memories through the documentary films of Great East Japan Earthquake. In: Koretsune S, Takakura H, editors. Door of disaster documentary film: Thinking ways of the sharing of memories through the documentary films of Great East Japan Earthquake (Saigai dokyumentarii eiga no tobira: Higashi nihon daishinsai no kioku to kiroku no kyouyuu wo megutte), Tokyo: Shinsensya; 2021, p.15-32.

[23] Kashihara T, Tsunoda R. Anyone can make a film with an Iphone (Aihuon de daredemo eiga ga dekiru hon). Tokyo: Kinema Zyunpousya; 2011.

[24] Baba A, Norio T. Digital Archives in Oversea (Kaigai ni okeru dezitaru aakaibu no doukou), Journal of the Institute of Image Information and Television Engineers (Eizou zyouhou media gakkaishi) 2020; 61-11: 1582-1585.

[25] Schwartz J. Records of Simple Truth and Precision: Photography, Archives, and the Illusion of Control. In: Blouin F, Rosenberg W, editors. Archives, Documentation, and Institutions of Social Memory, Ann Arbor: University of Michigan Press; 2007 p. 61-83.

[26] Harada K. Mizushima, H, editors. Hands, foots, eyes and ears: Practices and research for communities and video archives ( $\mathrm{Te}$ to asi to me to mimi - tiiki to eizo aakaibu wo meguru jissen to kenkyuu). Tokyo: Gakubunsha; 2018.

[27] Takeda N. Development of Video Aarchive Created from the Evacuees' Safety Net-making (Hinansya no seehutii netto zukuri kara eizou aakaibu seisaku he no hatten). In: Sekiya Y, Takakura $\mathrm{H}$, editors. Public Anthropology of Disaster Recovery (Sinsai hukkou no koukyou zinruigaku), Tokyo: University of Tokyo Press; 2019 p.55-86.

[28] Yanai T. Living in the Gray Zone: A thought on Tsukuba Video Archives (Haiiro titai wo ikinukeru koto: 'Tukuba eizou aakaibu' kara kangaeru). In: Sekiya Y, Takakura H, editors. Public Anthropology of Disaster Recovery (Sinsai hukkou no koukyou zinruigaku), Tokyo: University of Tokyo Press; 2019 p.34-54.

[29] Sato M. Documentary Film is a Visual Critique to Reality (Dokyumentarii wa eizou hyougen ni yoru genzitu hihan de aru). In: Sato M, Documentary Films are the Horizon of Movies (Documentarii ha eiga no tihei), Tokyo: Gaihuusya; 2001 p.13-43.

[30] Matsubara T, director. Nuclear Cattle (Hibaku ushi to ikiru) (Film). Osaka: Power Eye; 2016. http://www.poweri.ne.jp/hibakuushi/english/ Accessed 2 November 2020.

[31] Konishi H, director. Akahama Rock \& Roll (Film). Tokyo: UPICC; 2014. Accessed 2 November 2020 http://www.upicc.com/akahama_rocknroll/index.html

[32] Shrum W, Scott G. Video Ethnography in Practice, Los Angeles: Sage; 2017.

[33] Mead, M. Visual Anthropology in a Discipline of Words. In: Hockings P, editor. Principles of Visual Anthropology. $3^{\text {rd }}$ ed. New York: Mouton de Gruyter; 2003 p.3-10.

[34] Clifford, J. Introduction: Partial truths. In: Clifford J, Marcus EG, editors. Writing Culture: The poetics and politics of ethnography. Berkeley: University of California Press; 1986 p.1-26.

[35] Takakura H. Making Exhibition from Science Photography and Video (Tyosa syasin, gazou kara tenji wo tukuru: Genti to bokoku no simin wo tunagu ouyou eizou zinruigaku). In: Bundo D, Kawase I, Murao S, editors. Field of Film Technology (Fiirudo eizozyutu). Tokyo: Kokonshoin; 2015. p.126-141.

[36] Takakura, H. The Anthropologist as Both Disaster Victim and Disaster Researcher. In Bouterey S, Marceau LM, editors. Crisis and disaster in Japan and New Zealand. Singapore: Palgrave Macmillan; 2019 p.79-104.

[37] Sato, M. Being an observer - A critical view from the audience (Kansatusya ni tessuru: Kankyaku no naka ni umareru hihanteki siten). In: Sato M, Documentary Films are the Horizon of Movies (Documentarii ha eiga no tihei), Tokyo: Gaihuusya; 2001 p. 10-18.

[38] Watanabe S, director. Silent revolution (Odayaka na kakumei) (Film). Yamagata: Idehado; 2017. http://odayaka-kakumei.com/ Accessed 2 November 2020.

[39] Umemura T, director. Debris and Radio (Gareki to razhio) (Film). Tokyo: Folcom; 2014. https://www.311movie.com/ Accessed 2 November 2020.

[40] Souda K. Let's go out to town with a camera: for the theory on observation movies (Kamera wo motte, mati he deyou: 'Kansatu eiga' ron). Tokyo: Shueisha Intaanasyonaru; 2015.

[41] Otaka H. Great East Japan Earthquake and Japanese Film Industry: A bird's-eye view of the film industry nine months after the earthquake (Higashinihon daisinsai to nihon eigakai - Sinsai go kyuukagetu no eigakai wo hukan suru). The Movie Times (Kinema zyupou) 2012; 1601: 43-46.

[42] Maeno Y. Screening movies at disaster-hitted area: A report of the cinema screening Tour (Hisaiti de eiga wo utusu - sinemariin zyunkai zyoueikai rupo). The Movie Times (Kinema zyunpou) 2012; 1601: 58-63.

[43] Hasegawa T. Learning about Natural Disasters through the Eyes of Sciences: The Examples of Iwanami Movie "Tsunami" (in Japanese), Physics Education in University 2011; 26(2): 117-120. doi.org/10.11316/peu/17.3_117

[44] Weisenfeld G. Imaging Disaster: Tokyo and the visual culture of Japan's Great Earthquake of 1923 (Vol. 22). University of California Press; 2012.

[45] Imahashi E. Photo literacy: Photojournalism and reading ethics (Foto riterasii: Houdousyasin to yomu rinri). Tokyo: Chukosinsyo; 2008.

[46] Tasaka H. The possibility of Film Curatorship: Movie archives and festivals (Firumu, kyureesyon no kanousei: Eizou akaibu to fesutibaru). Bulletin of Tokyo Metropolitan Museum of Photography (Tokyo to Syasin Bizyutukan Kiyou) 2011 10: 11-15.

[47] Okajima H. Kokuritu eiga aakaibu - Sono genjyou to tenbou (The Present and Near Future of National Film Archive of Japan). Journal of the Japan Society for Digital Archive (Dezitaru aakaibu Gakkaisi) 2019 3-4: 370-374.

[48] Iizawa K. Digi-graphy: does digital technology kill photography? (Dezigurafi. Dezitaru ha syasin wo korosunoka). Tokyo: Chuokoronsya; 2014. 